\title{
Global perspectives on alcohol research: Facilitating interdisciplinary and international collaborations to address prevailing challenges
}

Alcohol is the most commonly used psychoactive substance in the world, as it causes I. 8 million deaths (3.2\% of all deaths) and accounts for $4 \%$ of the disease burden each year (World Health Organization [WHO], 2004, 20II). It is well documented that alcohol use is associated with a range of adverse outcomes (Baliunas, Rehm, Irving, \& Shuper, 20I0; Fisher, 20Iо; Lönnroth, Williams, Stadlin, Jaramillo, \& Dye, 2008; Rehm et al., 2009; Swahn, Bossarte, \& Sullivent, 2008; Tumwesigye \& Kasirye, 2005, 2006; WHO, 20Iо; Zablotska et al., 2006). Moreover, although data remain relatively limited, it is clear that the disease burden related to alcohol use is especially high among low-income and middle-income countries, where alcohol use rates are high due to limited implementation of public health policies and prevention strategies (WHO, 2007). It is a growing concern that this important public health problem remains largely unaddressed, especially in several of the subSaharan countries which have among the highest alcohol per capita consumption rates worldwide (WHO, 2004, 20II).

In its 2011 global status report on alcohol, WHO outlined alcohol monitoring and surveillance as key strategies for reducing the harmful use of alcohol (WHO, 20II). To implement these strategies, particularly in low- and middle-income countries, international collaborations can be particularly helpful and, indeed, instrumental. Research conferences are one way in which these collaborations are fostered. A good example is the thematic meeting of the Kettil Bruun Society for Social and Epidemiological Research (KBS), which was held in Africa for the first time in 2010 .

The thematic focus of that meeting was specifically on alcohol epidemiology and policy, and it presented a groundbreaking opportunity for interna- tional and interdisciplinary interaction and exchange on urgent and emerging alcohol-related issues, not only in Africa but also in other regions. The meeting enjoyed great international representation with participants from 22 countries, which greatly facilitated the exchange of global perspectives in alcohol research and prevention efforts. The success of the conference created momentum and focused significant attention on interdisciplinary and international research collaborations among representatives from academic institutions, community-based organizations, research-focused institutions and local and international government representatives, including WHO. Manuscripts presented at that meeting were subsequently invited for consideration for publication in this inaugural issue of the International Journal of Alcohol and Drug Research (IJADR).

The six articles included in this first issue that were also presented at the KBS meeting in 2010 outline intriguing advances in alcohol research across disciplinary approaches, populations and countries. Two of the articles examine issues pertaining to alcohol use among Ugandan populations, focusing specifically on socioeconomic determinants for heavy episodic drinking among university students (Stafström \& Agardh) and on alcohol intoxication before last sexual intercourse among adults (Tumwesigye, Wanyenze, \& Greenfield). These studies demonstrate, respectively, that socioeconomic status is linked to heavy episodic drinking among university students in Uganda and that alcohol consumption prior to sexual intercourse is relatively prevalent among sexually active men and women. Another article (Abikoye) presents the psycho-spatial predictors of hazardous drinking among drivers in Nigeria, and illustrates that there are numerous important risk factors associated with hazardous drinking in 
this group of drivers. A different scholarly approach is employed in another article (Schmidt \& Room), which examines the role of alcohol and inequity in the process of development based on ethnographic research of alcohol use in low- and middle-income countries. This study outlines the complexity of alcohol use as both a source and symbol of political tension and social class division. A cross-cultural examination is presented in an article (Wilsnack, Kristjanson, Wilsnack, \& Benson) that examines distress and drinking across 22 countries using data from Gender, Alcohol and Culture: An International Study (GENACIS). Wilsnack and colleagues found that psychological and interpersonal distress is linked to increased drinking, but that these associations were not driven by societal-level characteristics. Another article (Holmila \& Warpenius) examines a community-based approach for the prevention of alcohol-related injuries used in Finland (the Finnish Local Alcohol Policy; PAKKA). The intervention was evaluated using a quasi-experimental design with pretest and post-test, and found important impact across outcome measures, including reductions in alcohol availability to minors, increase in alcohol abstinence among minors, and changes in attitudes and knowledge on alcohol control measures. These studies will serve to inform the alcohol prevention research community and emphasize the need for cross-cutting studies that traverse interdisciplinary boundaries and methodologies to examine alcohol issues.

It is with great anticipation that we look forward to the annual KBS meeting in Kampala in 2013. The meeting will be an opportunity for further dialogue and exchange on global and emerging issues related to alcohol and other substance use, as well as a platform to articulate a vision for research in subSaharan Africa and other low-income regions of the world. Many important and emerging priorities are outlined in the articles presented in this issue and elsewhere, including alcohol marketing exposure; the role of alcohol use in violence, injuries and HIV transmission; and alcohol use in vulnerable populations, to list just a few examples (Swahn, Ali, Palmier, Sikazwe, \& Mayeya, 2oıı; Swahn, Ali, Palmier, Sikazwe, Twa-Twa, et al., 20II; Swahn, Palmier, Kasirye, \& Yao, 2012; Tumwesigye \& Kasirye, 2005; WHO, 2OII). These and other topics can be discussed at international meetings to illuminate important issues that require cross-cutting and multisectoral interventions and action.

It is of grave concern that alcohol and its adverse consequences remain understudied, given that alcohol use is one of the most significant risk factors for death and disability in sub-Saharan Africa. This problem is exacerbated by the fact that several of the countries in this region have some of the highest per capita consumption levels of alcohol in the world (Endal, 2009; WHO, 2004, 20II). Even more troubling is the research indicating that Uganda has the highest prevalence of alcohol-related negative consequences in cross-national comparative studies (Graham, Bernards, Knibbem, et al., 2oII; Graham, Bernards, Wilsnack, \& Gmel, 20II). The prevalence and urgency of these problems underscore the need for a more targeted vision for alcohol research, and also for the need for evidence-based policies and prevention efforts across sub-Saharan Africa.

This new journal can serve as an important platform for the dissemination of new findings in research, practice and policies that seek to address these issues. The journal, which is supported by KBS, as well as the Centre for Addiction and Mental Health (CAMH) in Ontario, Canada, and the National Institute on Drug Abuse (NIDA) in the United States, presents an exciting new option for authors to publish their scholarship on alcohol and other drug use. Moreover, the journal upholds a vision of promoting social and epidemiological research on alcohol and fostering a comparative understanding of alcohol use and alcohol problems in a spirit of international cooperation. The journal operates using an open access platform that is free of charge to authors as well as to their intended audience.

In conclusion, while we have successes to celebrate, such as this inaugural issue of IJADR and past and future KBS meetings, there are also many more discoveries to make and partnerships to foster in order to strengthen the impact of alcohol prevention efforts. The dissemination of our work needs to be more deliberate and we need to increase the reach of our findings to make them more accessible to policymakers. This new journal can address several of these critical gaps, but we should all contribute to making the priorities more visible in the regions of the world where the needs are most urgent.

Monica H. Swahn, PhD, MPH
IJADR Consulting Editor

Institute of Public Health, Georgia State University, Atlanta, U.S.A.

Nazarius Mbona Tumwesigye, PhD

IJADR Consulting Editor

Department of Epidemiology and Biostatistics, School of Public Health, Makerere University College of Health Sciences, Kampala, Uganda 


\section{References}

Baliunas, D., Rehm, J., Irving, H., \& Shuper, P. (2010). Alcohol consumption and risk of incident human immunodeficiency virus infection: A meta-analysis. International Journal of Public Health, 55, 159-166.

Endal D. (2009). Appeal for evidence-based alcohol policies in the region. Conference on the prevention of alcohol-related harm in East Africa, Arusha, Tanzania.

Fisher, J. C. (20I0). Can we engage the alcohol industry to help combat sexually transmitted disease? Journal of Public Health, 55, I47-I48.

Graham, K., Bernards, S., Knibbem, R., Kairouzm, S., Kuntsche, S., Wilsnack, S. C., . . Gmel, G. (20II). Alcohol-related negative consequences among drinkers around the world. Addiction, 106, I39I-405.

Graham, K., Bernards, S., Wilsnack, S., \& Gmel, G. (2OII). Alcohol may not cause partner violence but it seems to make it worse: A cross national comparison of the relationship between alcohol and severity of partner violence. Journal of Interpersonal Violence, 26, I503-1523.

Lönnroth, L., Williams, B. G., Stadlin, S., Jaramillo, E., \& Dye, C. (2008). Alcohol use as a risk factor for tuberculosis-a systematic review. BMC Public Health, 8, 28.

Rehm, J., Mathers, C., Popova, S., Thavorncharoensap, M., Teerawattanon, Y., \& Patra, J. (2009). Global burden of disease and injury and economic cost attributable to alcohol use and alcohol-use disorders. Lancet, 373, 2223-2233.

Swahn, M. H., Ali, B., Palmier, J. B., Sikazwe, G., \& Mayeya, J. (20II). Alcohol marketing, drunkenness, and problem drinking among Zambian youth: Findings from the 2004 global schoolbased student health survey. Journal of Environmental and Public Health. doi:IO.II55/20II/497827.

Swahn, M. H., Ali, B., Palmier, J., Sikazwe, G., Twa-Twa, J., Tumwesigye, N., \& Rogers, K. (20II). Early alcohol use and problem drinking among students in Zambia and Uganda. Journal of Public Health in Africa, 2. doi:I0.408I/ jphia.20II.e20

Swahn, M. H., Bossarte, R. M., \& Sullivent, E. E. (2008). Age of alcohol use initiation, suicidal behavior, and peer and dating violence victimization and perpetration among high-risk, sev- enth-grade adolescents. Pediatrics, 121, 297-305.

Swahn, M. H., Palmier, J. B., Kasirye, R., \& Yao, H. (20I2). Correlates of suicide ideation and attempt among youth living in the slums of Kampala. International Journal of Environmental Research and Public Health, 9, 596-609. doi:I0.3390/ijerph9020596.

Tumwesigye, N. M., \& Kasirye, R. (2005). Alcohol and its association with sexual abstinence, condom use and risky behaviour among unmarried young people aged I8-24 years in Uganda. African Journal of Drug and Alcohol Studies, 4, I7-3I.

Tumwesigye, N. M., \& Kasirye, R. (2006). Gender and the major consequences of alcohol consumption in Uganda. In I. Obot \& R. Robin (Eds.), Alcohol, gender and drinking problems (pp. I89-208). Geneva, Switzerland: World Health Organization.

World Health Organization (2004). Global status report on alcohol 2004. Geneva, Switzerland: Author. Retrieved from http://www.who.int/substance_abuse/publicatio ns/global_status_report_2004_overview.pdf

World Health Organization. (2007). Alcohol and injuries: A summary of the report from the WHO Collaborative Study on Alcohol and Injuries. Geneva, Switzerland: Author. Retrieved from http://www.who.int/substance_abuse/publicatio ns/alcohol_injury_summary.pdf.

World Health Organization. (2010). Global strategy to reduce the harmful use of alcohol. Geneva, Switzerland: Author. Retrieved from http://www.who.int/substance_abuse/msbalcstr agegy.pdf

World Health Organization (20II). Global status report on alcohol and health. Geneva, Switzerland: Author. Retrieved from http://www.who.int/substance_abuse/publicatio ns/global_alcohol_report/msbgsruprofiles.pdf

Zablotska, I., Gray, R., Serwadda, D., Nalugoda, F., Kigozi, G., Sewankambo, N., ... Wawer, M. (2006). Alcohol use before sex and HIV acquisition: A longitudinal study in Rakai, Uganda. AIDS, 20, II9I-II96. 